\title{
The Palgrave Handbook of Comparative Economics
}

\author{
2021. February 23.
}

A whole brand-new concept was made in Comparative Economics this year and luckily we had the opportunity to get to know the unique point of views in a newly published book The Palgrave Handbook of Comparative Economics by Elodie Douarin. Corvinus University of Budapest had a chance to discuss this exciting new approach with the most prestigious professors in Comparative Economics. Elodie Douarin from the College of London, Gerard Roland from Berkeley and Bruno Dallago from Trento helped us to understand the new theory. In the Corvinus side, Zoltán Ádám, András Székely-Doby and Judit Kálmán professors participated in the discussion. The moderator was Miklós Rosta, Head of Comparative and Institutional Economics Department.

Participants:

- Elodie Douarin, University College London: The Palgrave Handbook of Comparative Economics

- Gerard Roland, Berkeley: Comparative Economic History

- Bruno Dallago, University of Trento: The New Comparative Economics

\section{Commenters:}

- Ádám Zoltán, Head of Economic Policy Department, Corvinus University of Budapest

- Székely-Doby András, Corvinus University of Budapest

- Kálmán Judit, Corvinus University of Budapest, Hungarian Academy of Sciences

\section{Moderator:}

- Rosta Miklós, Corvinus University of Budapest

For introduction Miklos Rosta, the head of the Department of Comparative and Institutional Economics at the Corvinus University of Budapest said that Hungary and other post-communist countries have always been in transition when we look at their economic and political system. It is a never-ending story. That is why the comparative economy is a distinguished scientific field for the whole region. However, it is not easy to describe what is exactly Comparative Economics? The new Palgrave Handbook of Comparative Economics is showing how comprehensive this scientific field is and what can we learn from it. He names some key features of comparative economics. First, it focuses on institutions. Secondly, it comprehensively studies systems: the interaction of economic and political systems is scrutinized simultaneously. Third, it uses a comparative approach. Miklos Rosta states that based on the Handbook institutional economy, political economy and comparative economics are converging. Another key feature of comparative economics that it is not only wants to understand economic systems in theory, but it aims to give economic policy advice based on theoretical research.

Elodie Douarin is a professor at the University College London and author of The Palgrave Handbook of Comparative Economics handbook, which was released as an e-book this month. 42 scholars are reflecting at all, how exactly comparative economic has changed through decades. The book highlights that it is important not to exchange comparative economics with socialist, capitalist systems and to differentiate a 
central planning economy from a market economy. It is more important to recognize economies as "systems" which are a combination of characteristics by their political and economic institutions, history, policy choices. That is why she named key features of comparative economics, which are institutions, history, and complexity in the field. On the other hand, in terms of comparative economics is not just about economics perspective either because systems are complex, their outcomes and objectives are multiple, and their studies require a context-rich approach. Key in here is the pluri-disciplinarity.

In the handbook, part one the chapters are reflecting the historical field, discussing the evolution from comparative economic system to comparative economic.

In section two, we are looking at the comparative economic system as it is used still today in economic history.

Section three contains full coverage of the post-communist transition because of how important this topic was changing and shaping the transition.

Part four is about new comparative economics focusing on growth and formal institution in the global world view.

Part five, six, and seven are broadening the goals of the new economic system and new issues in methodologies and comparative analysis are addressed.

As a commentator, Ádám Zoltán, who is a professor at the Corvinus University of Budapest, highlighted the final chapters' main conclusion has three main topics. They argue that institutions matter, the postcommunist transition area is over but its lessons still matter, policies are inherently complicated and governments cannot control all relevant factors like history.

Bruno Dallagos' chapter in the handbook is a critic of comparative economics. The professors argue the fact that neither the old type of comparative economic system nor the new comparative economics is informed by a wide range of institutional observation and deep interest of institutions and outcomes that is why a compromise should be reached between the two. Interestingly, they argue about the old comparative economic system approach as a broader view because of the relation to the new modern systems.

According to Ádám Zoltán, possible additional considerations must be found in the methodological collectivism versus individualism methodology. He personally believes that economics and sciences are based on methodological individualism using the principle of utility maximization. The old type of comparative economic system is rather related to the methodological collectivist tradition. Kornai himself states this as well in his studies. Meanwhile, modern economics seems to be more engage in methodological individualism.

Ádám Zoltán highlighted the fact that one new type of comparative work, the traditional varieties of Capitalist approach, is mentioned in the handbook. It is very thought-provoking that Gerald Roland was using comparative history and culture to inform the modern comparative economic analysis. However, we need to ask the question: is this enough to legitimize the existence of comparative economics as a subfield of economics? Or maybe is it rather a unique approach?

The next presenter is Bruno Dallago from the University of Trento. In his chapter "The New Comparative Economics", the professor would not propose a compromise between the comparative economic system and the new comparative economics. Instead, he suggests a healthy competition with rivalry.

He also highlights the fact that comparative economics belongs to different systems and claims that new comparative economics has new criteria: efficiency. We are living in a time of systemic risks from electricity to internet risk and now in the pandemic risk. More and more, the environmental system is in danger as well due to climate change. Efficiency is a narrow criterion to understand how the economic system survives. China proved adaptation to very serious circumstances for a few thousand years. In this 
way, he asks the question: if we pursue efficiency, can we combat pandemics? Until when we can make exact economic calculations on what is convenient or not? Is the new comparative economics able to follow things and tell us what to do? And also, why countries want to become fully pledged market economics? For a very good reason: they all want a full-fledged market economy with efficiency. Overall, he summarizes that new comparative economics does not highlight the positive approach as it is weak, and comparative economic propose interesting problems.

After Bruno Dallago's speech, Judit Kálmán from the Corvinus University of Budapest commented on his chapter with the most catching idea, which is the healthy rivalry between the old and new comparative economics. Professors acquire a new review of the two sides and provide some argument about why is this healthy rivalry should stay. Judit Kálmán also criticizes the new comparative economic for lacking considerations of culture, social relations, and geographic features. However, Bruno and Sara acknowledged the new comparative economic as an important economical tool, they are criticizing the failure of providing a theory for the evolution of institutions. She suggests a compromise, just as Bruno did before, and states that the two comparative economics existence is justified.

She also highlights that Hungary is part of the debate today. In Hungary, development policies lived through governmental changes. Tremendous changes happened in few decades. Hungary is also part of NATO, EU that is why many aspects and differences can be written into stones in why's and how's. Despite all of this, Hungarian citizens have had paid a lot of political prices. Because of this reason, we need to care for indicators and involve society in economic development. For example, there is a pandemic. Every country's fatality rate and infected rates are different. Different political and economic systems are underlying factors on how countries, societies, governments treating their citizens. When it comes to recovery, there will be a question: why certain countries are winners or losers? A comparative approach in this matter is quite necessary, as it is emphasizing institutions, incentive norms, and cultures.

Gerard Roland, Comparative Economic History professor from Berkeley, was the third invited guest in the conference. First, he states that standard perspective economic history tends to lack comparative perspective as we tend to see economic history as millennial enthusiast stagnation that started with industrialization from the UK and then all around the world. Industrialization happened in countries with mostly free markets, private property, and institutions who were protecting private property rights. The question is if we look at resent history in the $20^{\text {th }}$ century; there is a failed experience of central planning, state ownership, and democratic communist regimes. However, there is one successful model: industrialization in western capitalism. He states that comparative economics was useful only for a few decades when socialist systems competed with capital systems. In this way, capitalism would ignore the "Chinese economic miracle" of the last 14 years. He emphasizes that Chinese economic performance is outstanding as the GDP is roughly equal to the US, but the population is 5 times larger, hence China is the number one export for the world and we all need to face the reality that China is a capitalist economy with a communist political regime. Observers thought when China started economic reforms, this would lead to political liberalization, nonetheless, the opposite occurred. What can be expected from the Chinese system in terms of climate change and the economy in the 21 st century? Gerard Roland claims that in order to understand China today, it is useful to go back to antiquity. This is the time when comparative economics comes into play and Chinas' economic institutional system was very different. To understand China today we need to look back to the $5^{\text {th }}$ to 1 st century BC, where there were two types of institutional systems all around the world. Egypt, China, Peru were more like central planning economies with status systems. Others like Mesopotamia, Athens, and Aztecs were more like market economies. 
Professor Roland prefers to compare Egypt's antiquity with Mesopotamia's antiquity as a crystal-clear example, as the two civilizations are not geographically far away from each other, however, their systems are different. Egypt was a territorial state, fertile with very modern conditions of production in the Nile. Resources were allocated by the government, inertial markets were limited and foreign trade was carried out by the government. Peasants did not have private property over the land and there were only public slaves (no private ones). Households were not allowed to hold slaves and the laws in ancient Egypt remain mainly in the state. There were elements of the meritocratic government and high aspiration from young people was to become a high-level official.

Mesopotamia was a city-state with a very strong heterogeneity of production between the north and southern Mesopotamia. Agriculture products and trade came from the southern part, luxury goods, stone, timber came from the north. Merchants, craftsmen worked on private bases with a strong market for land and slaves. The law in Mesopotamia tended to codify relations between citizens in particular conflicts over private property. Aspiration from young people was to become large landlords very different from Egypt. The young dynasty of China was more like Egypt with homogeneous production with a top-down law. There were very strong roles in the clan system and the emperor relations with clans and cities has a different meaning. In this way, we can see a very strong division in labor with a lot of tasks specialized craftwork in early production, and a very early introduction of population registration in cities, which exists today.

Overall, the comparative economic history research program reflects the answers before. There is a large database of quantified institutions in antiquity. Gerard Roland's handbook chapter documents some of the institutions, clustering around status versus market systems. However, they need more research in the area. Finally, yet importantly, András Székely-Doby from the Corvinus University of Budapest took the floor to comment on Professor Rolands' chapter. The amount of data for the chapters were immense, which creates room for analysis for non-democratic systems. While economics mainly discussing market economies, in some cases it neglects those without market institutions. He states that in order to incorporate economic analysis and frameworks, we need to look beyond current economic performances and historical issues as well. China is one of the most important actors in the area. Without China, it is impossible to create immense research. The reader can see through this chapter that how history is important and the transition from communism through the capitalist system is over. We cannot talk about socialist systems anymore, but their heritage exists. The more we learn about China the better we can understand how important its past. Bringing history back in economics is an important key element in the comparative economic area.

To conclude, there is no black or white development, which needs to be highlighted. There are no bad or good institutions. He assumes that everything depends on the historical context of the region. Interest does not allow good institution establishment. These are depending on the historical context.

So why do these institutional differences from antiquity matter? Cultural differences affect the past and future development of institutions. Institutions with a long historical background are essential for economic performance. We have to have multiple approaches and disciplines to raise the appropriate questions.

Fanni Barkóczi ${ }^{1}$

${ }^{1}$ Teaching Assistant at Economy and Public Policy Department

DOI: 10.14267/RETP2021.02.22 